American Journal of Pharmaceutical Education 2020; 84 (3) Article 7452.

\title{
RESEARCH
}

\section{Status of Pharmacy Ethics Education in Australia and New Zealand}

\author{
Stephanie Beshara, BPharm (Hons), ${ }^{a}$ David Herron, MPharmPH, BPharm (Hons), ${ }^{\mathrm{b}}$ \\ Rebekah J. Moles, PhD, BPharm, DipHospPharm, ${ }^{a}$ \\ Betty Chaar, $\mathrm{PhD}$, Master of Health Law (MHL), BPharm ${ }^{\mathrm{a}}$ \\ ${ }^{\text {a }}$ The University of Sydney, Sydney Pharmacy School, Sydney, Australia \\ b James Cook University, College of Medicine and Dentistry, Queensland, Australia \\ Submitted November 13, 2018; accepted August 1, 2019; published March 2020.
}

\begin{abstract}
Objective. To explore models of teaching in, resources available to, and delivery of a standardized course in pharmacy ethics.

Methods. An email invitation was sent to the educator responsible for teaching pharmacy ethics at each of 19 institutions in Australia and New Zealand. Over a six- to eight-week period, semi-structured interviews were conducted in person, by email, or by phone, and were audio-recorded where possible, transcribed verbatim, and entered into data analysis software. Using an inductive analysis approach, themes related to the topics and issues discussed in the interview process were identified.

Results. Of the educators invited to participate, 17 completed an interview and were included in this study. Participants reported a paucity of resources available for teaching pharmacy ethics at schools in Australia and New Zealand. Compounding this issue was the lack of expertise and ad-hoc process educators used to create their courses. Assessment methods varied between institutions. Participants felt schools needed to move toward a more standardized pharmacy ethics course with clear and defined guidelines.

Conclusion. This study identified many areas in pharmacy ethics that need improvement and revealed the need to develop resources and course structure that adhere to the highest level of Miller's pyramid, while using known frameworks to evaluate ethical competency.
\end{abstract}

Keywords: ethics, course structure, resources, teaching, Miller's pyramid

\section{INTRODUCTION}

Ethical decision-making in pharmacy practice is a fundamental skill that pharmacists must have to deliver appropriate, patient-centered care. Despite the importance of this topic, the educational framework within which the learner engages with the subject varies across different curricula around the globe. ${ }^{1-4}$ Traditionally, pharmacy courses were almost exclusively science-oriented. However, in recent decades, greater focus has been placed on students developing clinical skills (eg, therapeutics, pathology interpretation), as well as skills in patient-centered care (eg, communication, empathy) in order to receive a balanced education. ${ }^{5-7}$ It follows therefore, that more attention would need to be paid to ethical decision-making in undergraduate training given it is a fundamental underpinning of pharmacists' everyday practice. However, the paucity of literature related to this topic does not

Corresponding Author: Betty Chaar, The University of Sydney, Sydney Pharmacy School, Pharmacy and Bank Building (A15) Science Rd., Sydney, Australia 2006. Tel: +61-2-9036-7101. E-mail: betty.chaar@sydney.edu.au support this. Some academics have reported on models of teaching ethics in pharmacy as patient-centered care becomes a focus, but analysis and evaluation remain scarce. ${ }^{8}$

The International Pharmaceutical Federation (FIP) published a global framework in 2006 stating that ethical and professional practice is a cornerstone of pharmacist competency. ${ }^{9}$ The FIP outlines the professional obligations expected of pharmacists, which center on the core bioethical principles of respect for autonomy, beneficence, non-maleficence, and justice, to guide pharmacists in their interactions with the broader public. ${ }^{9}$ In addition, and prior to this framework being available, other countries had provided their own competency frameworks. For example, the National Competency Standards Framework for Pharmacists in Australia, over its last three iterations (2012, 2015, and 2016), sets a standard to instill "professional and ethical practice" in prospective graduates, preparing students for life beyond a didactic learning environment. ${ }^{10}$ The Australian Pharmacy Council (APC), the accrediting organization in Australia, mandates that teaching institutions to integrate the teaching of pharmacy ethics into the curriculum as a criterion to be met for 


\section{American Journal of Pharmaceutical Education 2020; 84 (3) Article 7452.}

pharmacy accreditation, built on the abovementioned competency standards. ${ }^{11}$ The current version features the requirements for teaching of ethics in "Learning Domain 5: Health care systems and the roles of professionals." 12

Domain 5 states that "for pharmacy graduates to be able to practice effectively, efficiently, and confidently they need to know about, understand and have some of the skills to operate within health care systems, alongside and together with other health professionals and other scientists. They need to have an appreciation of their responsibility to share and contribute to the knowledge of others." 12 The indicative elements within this domain have a focus on the role of the pharmacist in the health care system. They dictate that students have an understanding of how professional ethics allow them to fulfil their duty of care to the patient through application of specific standards and guidelines for professional practice. ${ }^{12}$

Although the above frameworks and organizations direct that pharmacists require this core skill to practice effectively, it was not clear how this was to be achieved. One United Kingdom study evaluated the literature relating to the scope of pharmacy ethics and identified a lack of cohesion between teaching bodies on how best to implement these concepts to ensure ethical competence. ${ }^{13}$ The implications of diverse teaching models used by institutions is also outlined in a recent study by Myers, wherein a variety of student responses to ethical scenarios demonstrated a rift between what was taught and what was learned. ${ }^{14}$

A 2005 comprehensive review analyzing medical ethics education in the United States attempted to reconcile the disconnect between the types of teaching methods that should be employed and the current teaching formats described in some empirical studies. ${ }^{15}$ The authors concluded that teaching ethical decision-making should be "viewed as a process," with emphasis on group discussions, particularly when implemented as an elective course, as these course structures have been proven to elicit the greatest increase in a student's moral reasoning skills. ${ }^{15}$ This is supported in the pharmacy literature, with some reported methods of integrating pharmacy ethics into the curricula identified as: debate, team-based approaches, use of legal cases, and dilemma discussions. ${ }^{2,3,16-18}$ These teaching modalities and their associated assessment tasks can be categorized into Miller's model of competence, which outlines four distinct levels of learning in a bid to achieve competence. ${ }^{19}$ The purported "success" of these methods, however, has not been reliably measured with a validated tool, but rather hinged on the feedback and opinions of the students in each study.

To reach competence according to Miller, the learner goes through several phases of development: first grounded in "knows," through a progression to "knows how," then a transition to "shows how," with the ultimate goal being "does." The analysis of legal cases as a method of teaching ethics, for example, represents the ground level of Miller's pyramid as a "knows" approach, ie, simply possessing knowledge about legal frameworks without the opportunity to apply decision-making skills. ${ }^{20,21}$ As is well recognized, not all laws are ethical and vice versa.

Discussion and team-based learning aim to actively engage the learner with the material by sharing opinions and perspectives, thereby falling under the banner of "knows how" in Miller's pyramid, describing the theoretical "application of knowledge." 20,21 This type of learning can be augmented with other approaches, such as casebased or problem-based learning, debate, and simulations, thereby elevating the learner to the "shows how" level through the demonstration of skills learned in discussions. The gold standard of Miller's pyramid rests atop at the "does" level wherein performance of the individual is assessed by directly observing behavior in practice, to discern knowledge and skills in a real or practice clinical setting. ${ }^{20,21}$ Miller's model differentiates competence from performance at this level. ${ }^{21}$

In the United Kingdom, a project entitled Advancing the Provision of Pharmacy Law and Ethics Teaching (APPLET) was launched in 2003 with an overall aim of developing standardized pharmacy ethics curricula across all schools in the United Kingdom and supporting teachers within pharmacy schools to assist students to explore the ethical complexities faced in modern practice. ${ }^{22}$ The program involved an analysis of the current curricula within pharmacy schools in the United Kingdom, as well as the development of communal resources that may be accessed by teachers via a website. ${ }^{22}$ This initiative was well received and began to successfully unify the approach and resources for the teaching of pharmacy ethics in the United Kingdom. However, the loss of funding for this project after three years signaled a marked loss of impetus for the APPLET project and a subsequent decline in research output in this field aside from individual researchers or small groups reporting the outcomes of institution-specific interventions. $^{22}$

Unlike the APPLET project in the United Kingdom, research into ethical education in the United States has been very much based on interventions conducted in individual schools reported by individual researchers or small groups. ${ }^{3,23-26}$ While such work is undeniably valuable, there is still no clear consensus on the gold standard for teaching students ethical decision-making skills in pharmacy.

From an Australian perspective, there is little literature in relation to curricula building in the context of teaching and learning in pharmacy ethics. While issues 


\section{American Journal of Pharmaceutical Education 2020; 84 (3) Article 7452.}

pertaining to professional ethics in practicing pharmacists have been examined in the Australian practice setting, there is little or no research that has explored specifically the teaching in these areas in Australia or its close neighbor New Zealand. ${ }^{27-30}$

This study sought to fill this gap, paving the way for establishing a foundation for future work into curriculum development. Exploring the experience and perspectives of key stakeholders involved in pharmacy education can provide valuable insight into the current status of the teaching of ethics in pharmacy programs in Australia and New Zealand. To achieve our objectives, we sought to identify the material being taught, the method or model in which the material is being delivered, and the expertise of the staff involved in the teaching of this material.

The aim of this paper was to explore the pharmacy educational strategies adopted for teaching ethics in pharmacy in tertiary institutions across Australia and New Zealand. The objectives for this study were to explore models of teaching, resources available, and needs for the delivery of a standardized course in pharmacy ethics.

\section{METHODS}

This was a qualitative study using semi-structured interviews (SSIs) conducted with questions specifically related to the objectives of this study, The Consolidated Criteria for Reporting Qualitative research item tool (COREQ-32) was used to ensure rigor, accountability, and adherence to established research methods. ${ }^{31}$ Interviews were conducted using an interview protocol (Appendix 1) based on the existing literature, objectives of the study, and the APC accreditation criteria. ${ }^{12,22,32-40}$ The SSI method was chosen as it provided a defined framework for the interview. Questions (with prompts) were open-ended, allowing participants to freely express their opinions. All interviews were de-identified and stored securely. Interviews were audio-recorded (except for interviews conducted via email), transcribed verbatim, and entered into NVivo, Version 11 (QSR International, Melbourne, Australia) for management of qualitative data. $^{41}$

We identified educators in Australia and New Zealand with experience in and responsibility for teaching ethics in pharmacy programs and invited them to participate in the study. There were 17 institutions with pharmacy programs in Australia and two in New Zealand at the time this study was conducted. Interviews were conducted over a period of six to eight weeks between July and September 2018. Interviews were conducted in person, by email correspondence, or by telephone. Consent was acquired from participants prior to beginning the interview or in writing via email. Approval for this study was granted by The University of Sydney Human Research Ethics Committee.

A thematic analysis method was used, which involved an inductive approach where initial codes were generated iteratively as themes emerged from the data collected. Transcripts were analyzed using the Srivastava \& Hopwood method of thematic analysis and coded in NVivo. ${ }^{41,42}$ Inductive analysis is regarded as the purest form of thematic or qualitative content analysis. ${ }^{43}$ It is particularly suited to allowing themes to emerge from the data rather than imposing set categories for themes prior to data collection and analysis. ${ }^{42}$ The role of iteration lends itself to what is known as a deeply reflexive process, and is vital to analyzing the depth of the data and creating meaning, while also allowing for refined focus to take place. ${ }^{42}$ This makes it an ideal analysis method for SSIs such as the ones conducted in this study where themes emerged in accordance with topics and issues discussed in the interview process. ${ }^{42}$

A primary coder was responsible for initial familiarization with the data through multiple readings of the transcripts. Following this, other members of the research team independently coded a sample of the transcripts. Once themes began to emerge, consultation with the broader research team allowed for further refining.

Categories were further refined until a defined framework was developed. The software was then used to develop a matrix to assist with analysis. Analysis of the data allowed both common themes as well as discrepancies to be identified and explored. Consensus on the final themes was reached after further discussion with the research team.

\section{RESULTS}

Interviews were conducted with 17 pharmacy participants (Table 1). One additional interview was conducted; however, the content was deemed irrelevant as the participant predominately focused on the law.

Five key themes emerged from analysis of the interview transcripts: scaffolding of courses in pharmacy ethics (ie, course/curriculum structure description), assessment of ethical competence, expertise of instructors, lack of resources, and recommendations for the future. Quotes related to each theme are presented in Tables 3-7.

\section{Lack of Scaffolding of Pharmacy Ethics Courses}

The first theme that emerged from the interviews was the lack of scaffolding of courses in pharmacy ethics (Table 2). The majority of participants struggled to describe a pedagogical rationale for the structure of their pharmacy ethics program. Some focused on specific details about the content of their program without providing a broader perspective, eg, how the course fit within the 


\section{American Journal of Pharmaceutical Education 2020; 84 (3) Article 7452.}

Table 1. Background Information on Faculty Members Invited to Participate in Interviews Regarding the Teaching of Pharmacy Ethics in Australia and New Zealand

\begin{tabular}{|c|c|c|c|c|}
\hline \multirow[b]{2}{*}{ Tertiary Institution } & \multirow[b]{2}{*}{$\begin{array}{c}\text { Years of Experience in } \\
\text { Teaching Pharmacy Ethics }\end{array}$} & \multicolumn{3}{|c|}{ Asked to Participate } \\
\hline & & Accepted & Declined & $\begin{array}{l}\text { Did not } \\
\text { respond }\end{array}$ \\
\hline Charles Darwin University & 6 years & $\checkmark$ & & \\
\hline Charles Sturt University & 11 years & $\checkmark$ & & \\
\hline Curtin University & 4 years & $\checkmark$ & & \\
\hline James Cook University & $\begin{array}{l}4.5 \text { years } \\
18 \text { years (law) }\end{array}$ & $\checkmark$ & & \\
\hline Monash University & 2 years & $\checkmark$ & & \\
\hline The Queensland University of Technology & 3 years & $\checkmark$ & & \\
\hline Royal Melbourne Institute of Technology & 4 years & $\checkmark$ & & \\
\hline The University of Auckland & 2 years & $\checkmark$ & & \\
\hline The University of Canberra & 5 years & $\checkmark$ & & \\
\hline The University of New England & $\begin{array}{l}<1 \text { year } \\
(10 \text { months })\end{array}$ & $\checkmark$ & & \\
\hline The University of Newcastle & 10 years & $\checkmark$ & & \\
\hline The University of Queensland & 5 years & $\checkmark$ & & \\
\hline The University of South Australia & $\begin{array}{l}3 \text { years } \\
2 \text { years }\end{array}$ & $\checkmark$ & & \\
\hline The University of Sydney & 13 years & $\checkmark$ & & \\
\hline The University of Tasmania & 2 years & $\checkmark$ & & \\
\hline The University of Western Australia & 2 years & $\checkmark$ & & \\
\hline Griffith University & N/A & & & $\times$ \\
\hline The University of Otago & N/A & & & $x$ \\
\hline La Trobe University & N/A & & $x$ & \\
\hline
\end{tabular}

pharmacy curriculum as a whole. In describing their courses, some respondents were resigned to the fact that their ethics course structure was fractured, disjointed, and undifferentiated, and was quite often simply mixed in with teaching of the laws of the profession.

No participant reported having a defined, standalone ethics course at their institution. All educators confirmed that the ethics component of their school's curriculum served as a minor addition to other broader-scoped courses (commonly the law course, but sometimes clinical or therapeutics courses). In most cases, ethics was taught as an afterthought, or at most, a brief overview in the form of lecture materials provided to students. Some participants even admitted that the topic of ethics existed in name only at their school, with very little content in this area delivered to students.

Most participants did not refer to any benchmark or accreditation standards such as APC standards or a code of ethics. Instead, they seemed to be working on an ad-hoc basis in terms of ethics content. For example, one participant explained how they taught ethics content by improvising ethical scenarios during their lectures, using values of sympathy/empathy to illustrate ethical behavior (Table 2). Some remains of a traditionalist science-focused

Table 2. Participant Quotes About Theme 1: Scaffolding of Courses in Pharmacy Ethics

"There is one lecture which covers both law and ethics. That's all ..."

"We talk about the pillars of ethics ... but it is not in any great depth"

"We don't have ethics as a specific separate topic, but we try and incorporate it into therapeutics"

"Ethics is intertwined with the law"

"[We have chosen] a chaplain to talk to them about philosophy to look at broader ethical concepts"

"No guidance is provided by the APC on what to actually teach, which just leaves us to our own devices"

"We just get to talk about the four principles of bioethics and reflect on a couple of very basic scenarios. Actually, I think we use some articles in the [Australian Pharmacist] journal" 


\section{American Journal of Pharmaceutical Education 2020; 84 (3) Article 7452.}

approach to curricula design, where ethics (as part of the pharmacy practice discipline) was not introduced until later in the course, was commonly reported. In these programs, a common, science-based first-year preceded an in-depth focus on pharmacy practice in the second year.

Some educators blamed the APC for lack of direction in this area and not outlining a defined set of teaching activities for ethics. While science-based aspects of the curriculum (eg, pharmacology) have tangible guidelines, the teaching of ethics was typically based on instructors' anecdotal experience, with no clear pedagogical scaffolding. As reported by participants, this lack of direction left educators to construct their own version of an ethics course with whatever resources were at hand.

Teaching methods and content used were reportedly self-selected or decided upon by the participants based on what they personally believed would work rather than on research. When describing the types of resources used, participants felt confident in explaining their personal rationale for their materials. Others, however, seemed less confident in explicitly stating which resources they had used to form their course structure. One participant (see Table 2) invited a chaplain into the classroom to explain the broad principles of ethics to their students.

A common theme across many tertiary institutions was the use of didactic lectures followed by associated tutorials and workshops to teach ethics. Many felt the lecture-workshop combination was an effective approach to delivering material and subsequently engaging students in conversations about ethics. However, none of the institutions had a standardized approach as to how they implemented and conducted their tutorials/workshops on ethics, resulting in significant variability between university programs.

\section{Assessment of Ethical Competence}

The second most pertinent theme that arose from this study was the assessment of ethical competence (Table 3 ). Although many academics could describe the types of rubrics used in the assessment of the practicum component of their ethics course, a significant majority could not explain the rationale behind the rubric. Some participants reported using a rubric created by a previous coordinator, while others reported creating a new rubric in house to use in assessing student performance in a new ethics course.

Assessment types varied widely between institutions. Many employed "written reflections", while others used short-answer questions on scenarios describing ethical dilemmas in practice. Almost all participants acknowledged that multiple-choice questions were used at some stage in their program to assess students' basic knowledge of principles. However, many recognized this was an ineffective means of assessing true ethical decision-making competence. A few managed to reach the "shows how" level of Miller's pyramid by incorporating simulated-patient approaches to teaching ethics. ${ }^{20}$

\section{Lack of Expertise in Ethics Among the Instructors}

The next theme was the expertise of instructors (Table 4). The majority of participants reported a lack of training in professional ethics at any stage of their careers. Although highly educated in their own fields, the majority of educators interviewed in this study had no previous or very minimal training in professional ethics. Many reported a desire for future training and education in this area.

A lack of training in professional ethics was also correlated to a general unfamiliarity with variant forms of the profession's Code of Ethics. Only two educators could reflexively recognize the principles in the Code of Ethics. Others either gave no credence to the code or had a more general medical ethics perspective.

Table 3. Participant Quotes About Theme 2: Assessment of Ethical Competence

"I have an assessment item that is all vignettes and multiple choice"

"There's multiple choice, arguments, and also performance-type tests"

"I primarily use an ethical scenario as a long-answer question"

"There's no written exam or anything like that ... we do MCQ-type [multiple-choice question] or short answer questions particularly in second and third year"

"I tend to use a sort of more generic medical ethics perspective rather than a specific document"

"Materials are assessed in OSCEs [Objective Structured Clinical Examinations] and final assessments"

"There's a component of ethics in an assignment"

"The assessment is as a reflection - it's a reflective practice exercise for their practicum where they need to identify an ethical dilemma and work through it"

"There's no explicit exam-based, either oral or written, questions in fourth year"

"In the exam students were asked to comment on a couple of scenarios using basic ethical theory that they had been given" "I can do short essays if I give them a case" 


\section{American Journal of Pharmaceutical Education 2020; 84 (3) Article 7452.}

Table 4. Participant Quotes About Theme 3: Expertise of Instructors

"I have no formal qualifications ... this certainly isn't my area of expertise"

"I don't have any particular expertise in ethics"

"How did I get by job here? Purely by accident"

"I was given the job of teaching forensics. . .and I've picked up the teaching of ethics within the last couple of years"

"I don't know of any of my colleagues who have an ethics background"

"I came to be teaching in this area because the previous unit convener left"

"I haven't actually got any other formal qualifications with it"

"I did my PhD on pharmacy ethics, so naturally that took me into teaching pharmacy ethics"

This individualized approach to teaching ethics principally relied on three variables: the educator's themselves, the educator's knowledge or lack thereof, and the circumstances of the educator's appointment to the role. Some young, inexperienced educators were commonly handed the course without having formal qualifications in the area of ethics or first being required to complete training. In one instance, a participant recalled having had the most knowledge of ethics in the room as the basis for their selection as coordinator (Table 4).

\section{Lack of Resources to Teach Ethics}

Another common theme among all participating educators was the paucity of resources allotted for ethics education in pharmacy (Table 5). Academics described situations where they had little to rely on, with many opting to share information among themselves in an effort to create an ad-hoc resource that was easily accessible and implementable.

Given this lack of resources, most of the educators had compiled a cache of various journal articles, clippings of recent news articles, law and ethics textbooks written by overseas authors, international case studies, and the Code of Ethics to use in creating their ethics curriculum. One resource that was mentioned by several participants was a series in the Australian Pharmacist entitled "Ethical Dilemmas" that they used to guide topics and discussions. $^{32-40}$

\section{Recommendations for the Future of Pharmacy Ethics Education}

The last theme was recommendations from participants on the teaching of pharmacy ethics in the future (Table 6). Most of the participants were clear and direct in their responses when questioned on their vision for the future. The general consensus was in support of the development of a standalone ethics course designed with clearly defined structure and content. Some ruminated on the common grouping of ethics with other subjects and stressed that ethics must be seen as a standalone topic in order to properly teach the subject.

As a unique way to teach the course, some proposed the idea of an interprofessional education scheme wherein an array of health disciplines could learn about ethics together instead of separately. Some advocated for a course where students would initially learn together with other professions about ethics, then later receive specialized instruction in the pharmacy classroom.

All participants strongly advocated for formally recognized, standardized resources to be made available

Table 5. Participant Quotes About Theme 4: Lack of Resources

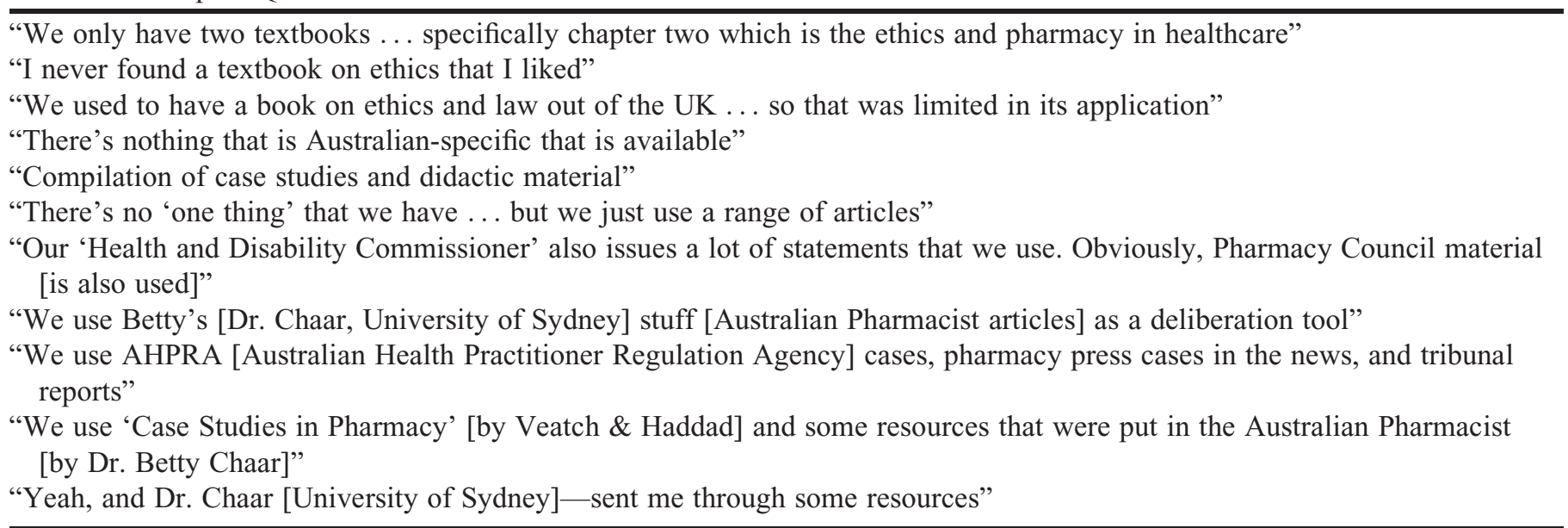




\section{American Journal of Pharmaceutical Education 2020; 84 (3) Article 7452.}

Table 6. Participant Quotes About Theme 5: Recommendations for the Future

"I'd actually like a textbook that is hard copy and electronic, so an e-book. I would like it to be balanced between some basics about ethics, some application of ethics, and some case studies that they can work through and only get the answers online, so not in the book [hard copy]"

"I think ethical thinking is probably the most they struggle with. . .it's probably also the thing that I believe is probably done poorly throughout Australia"

"A text or some sort of resource would definitely be useful, something that's Australian-centric"

"An e-resource would definitely be the most convenient for online teaching. For online teaching an e-resource is definitely the most appropriate; it is cheaper and more accessible for students, and it makes it a lot easier to deliver that material"

"The way ethics just gets bundled up sometimes with forensics...there's some really important things with forensics, but they're also separate"

"I think the most powerful and most costly resource would be an e-resource... that might be the most involving of the students"

"Teaching ethics. .. reaches out across a lot of disciplines within the healthcare professions. So, I think that should be maybe developed more"

to faculty members. Many saw the potential benefit in creating a course wherein future pharmacists could further develop their skills when guided by a uniform, standardized course. Many also believed that a step in this direction would open the possibility of more resources being created for the sole purpose of teaching ethics.

Additionally, the need for a substantive local resource was also profound within this group. In light of technological advances, many of the participants favored an e-resource, which they believed would be more accessible by students and faculty members alike. An eresource would also allow faculty members to offer an online component to the course that could successfully engage students with the content in a new and creative way, as opposed to a standard paper-based textbook.

\section{DISCUSSION}

This study is the first to explore pedagogical strategies in teaching pharmacy ethics in tertiary institutions across Australia and New Zealand. It is also a timely study in view of the revision of APC accreditation criteria, which appear to place more emphasis on training in pharmacy ethics in light of the increased focus on patientcentered care. ${ }^{44}$ Although professional frameworks specify the basic need to develop ethical competence in pharmacists, our study revealed a fractured and disjointed educational pedagogical landscape in Australia and New Zealand. $^{9-11}$

The five themes that emerged from the data collected gave us critical insight into the current setting within which educators practice. Specifically, this study revealed the struggle educators face in teaching pharmacy ethics, having little or no underpinning pedagogy and lacking resources. The paucity of texts that exist on pharmacy ethics proved challenging for educators but instigated some creativity on their part in finding ad-hoc resources, such as newspaper articles. This lack of resources on ethics is in contrast with other healthcare professions such as medicine, where there is a plethora of resources in the form of medical ethics journals, textbooks, videos, online courses, etc. $^{45-50}$ Pharmacy does not yet have a standardized resource or a specific journal to address contemporary issues in and teaching of pharmacy ethics in Australia and New Zealand. This challenge faced by pharmacy ethics educators could potentially be redressed at a national level by creating a repository of articles, textbooks, and/or creation of a journal.

Most literature that speaks to pharmacy ethics is presented as codes or statements from peak professional bodies or as opinion pieces featured in journals. ${ }^{9,51-54}$ The reason for this void rests on the common belief that pharmacy ethics is generally based on common sense, and as such, requires no formal education or study to teach. One respondent based their teaching on this notion and used sympathy/empathy as a method in teaching ethics. This may be an effective approach; however, it could miss foundational instruction in structured ethical decisionmaking.

The expertise of educators was a major point of concern in this study. Most respondents had no training in professional ethics (Table 4). This is all the more reason a standardized approach to the teaching of professional ethics in pharmacy would be beneficial for training new generations of pharmacists in Australia. The unstructured approach taken by the academics interviewed in this study appeared to have created extensive variability in the delivery and content of the ethics component of the pharmacy curriculum and raised a myriad of issues. The participants' lack of expertise meant teaching was often self-directed and grounded in personal experience rather than adherence to any teaching protocols. In the United Kingdom, APPLET reported that only some schools employed faculty members with the appropriate qualifications in professional ethics, with many institutions opting to defer to 


\section{American Journal of Pharmaceutical Education 2020; 84 (3) Article 7452.}

newly hired faculty members to teach the ethics component of the course. ${ }^{22}$ This stands in stark contrast to the teaching of traditional science-focused courses. Globally, a course that is grounded in traditional principles, such as the sciences, has clear standards which appropriately qualified educators are expected to teach. ${ }^{55-57}$ It would be extraordinary for a traditional course to be delivered by an unqualified educator or without a clear set of guidelines for teachers to follow in structuring their course. Our study uncovered multiple instances where teaching of pharmacy ethics existed as a morass of information, with no clear delineation of course structure or learning objectives.

On the other hand, the preference the participants' expressed for engaging students in meaningful discussions about ethics rather than assigning masses of didactic materials for them to read, suggested that educators were expanding their role and moving beyond the traditional approach taken previously in teaching ethics. ${ }^{13}$ This is supported in contemporary literature relating to teaching techniques, where it is regarded that engaging students in discussion or debate encouraged responsible dialogue and reflective articulation of a justifiable point of view. ${ }^{3,58-60}$ However, when it comes to assessment, only one university could cite a validated or well-structured measure to assess ethical competence at the "shows how" level, which raised the question of whether true ethical competence was being achieved. ${ }^{19-21}$ This is usually achieved only in a real-life clinical setting or simulation. One participant reported that simulation was the model of assessment at their school of pharmacy and that a grading rubric based on the decision-making processes was used. This method appeared to mirror real-life encounters and be based on solid pedagogy; hence, we recommend that this method be adopted by all educators in pharmacy ethics. $^{61-64}$

We believe it would be particularly useful to adopt a "train-the-trainer" approach to prepare all educators who are assigned to teach pharmacy ethics. Such standardized training of educators in pharmacy ethics could be a muchneeded solution to the problems faced by pharmacy ethics faculty members in Australia and New Zealand. This approach could also facilitate creation of a standardized ethics course that could be implemented in all pharmacy schools across Australia and New Zealand. Such a standardized course would ensure quality teaching of ethics within a defined structure that then would enable educators to communicate, consult, and collaborate effectively with one another. The "train-the-trainer" approach is a well-founded method of unifying and strengthening teaching and assessment strategies in many settings, including other healthcare professions, and could improve the teaching of pharmacy ethics. ${ }^{65-69}$
There were several strengths that can be attributed to this study. Importantly, we captured perspectives of the majority of participants, with 16 of the 19 pharmacy schools in the two countries represented; hence, findings are reasonably generalizable within Australia and New Zealand. We also had major consensus in the themes and issues discussed, with little discrepancy across the board. Further, using the COREQ-32 item tool added to the rigor and credibility of this study by giving us insight into the research team, relationships with participants, and contextualizing the results within the backdrop of this study. ${ }^{31}$ Limitations of this study included that some interviews were completed via email and therefore lacked the spontaneity of a face-toface interview, as well as the opportunity to prompt the participant and pursue more in-depth enquiry.

\section{CONCLUSION}

Although traditionally grounded in a science-based foundation, pharmacy education (including pharmacy ethics), has been in a state of change over the last few decades, as the focus of the profession shifts to patientcentered care. The findings of this study indicated potential for many suggestions to be adopted for improvement of the status quo related to the current state of teaching of pharmacy ethics in Australia and New Zealand. One approach to improving student instruction in pharmacy ethics is the development of a "train the trainer" program for faculty members. This is one way of addressing the lack of expertise in this field while fostering the professional development of academics in this area. Coupled with this would be the development of contemporary, region-specific materials. Another means by which this objective could be achieved involves clearer articulation of the educational requirements for entry-level pharmacists with regards to ethics by the registering body, the APC. This in turn would highlight the importance of ethics instruction in the pharmacy curriculum, with the end goal of more time and resources being allocated to the teaching of this topic.

\section{REFERENCES}

1. Chávez H, Sánchez P, Telha C, Puelles C, Thielemann AM. Applications of internet to teaching - learning through the use of web pages. Pharm Educ. 2002;2(4):205-208.

2. Hasan S. Teaching ethics to pharmacy students using a team-based learning approach. Pharm Educ. 2011;11(1):99-106.

3. Hanna LA, Barry J, Donnelly R, et al. Using debate to teach pharmacy students about ethical issues. Am J Pharm Educ. 2014;78(3):1-8.

4. Henning MA, Malpas P, Ram S, et al. Students' responses to scenarios depicting ethical dilemmas: a study of pharmacy and medical students in New Zealand. J. Med. Ethics. 2016;42(7):466-473.

5. Hall K, Musing E, Miller DA, Tisdale JE. Experiential training for pharmacy students: time for a new approach. Can J Hosp Pharm. 2012;65(4):285-293. 


\section{American Journal of Pharmaceutical Education 2020; 84 (3) Article 7452.}

6. Toklu HZ, Hussain A. The changing face of pharmacy practice and the need for a new model of pharmacy education. $J$ Young Pharm. 2013;5(2):38-40.

7. Koehler T, Brown A. Documenting the evolution of the relationship between the pharmacy support workforce and pharmacists to support patient care. Res Social Adm Pharm. 2017;13(2):280-285.

8. Angel LA, Simpson MD. Report of best practice: development of an ethics manual as an integral component of undergraduate curriculum and application for graduates and practitioners. J Learn Design. 2007;2(1):1-13.

9. The International Pharmaceutical Federation. FIP Statement of Professional Standards: Codes of ethics for pharmacists (Standards 2014 v3.0). Published August 2014. https://www.fip.org/file/1586. Accessed March 10, 2020.

10. Pharmaceutical Society of Australia. National Competency Standards Framework for Pharmacists in Australia (National Competency Standards 2016). Published March 2016. https:// www.psa.org.au/wp-content/uploads/2018/06/NationalCompetency-Standards-Framework-for-Pharmacists-in-Australia2016-PDF-2mb.pdf. Accessed March 10, 2020.

11. The Australian Pharmacy Council. About APC. https:// www.pharmacycouncil.org.au/about-apc/. Accessed

March 10, 2020.

12. The Australian Pharmacy Council. Accreditation Standards for Pharmacy Programs in Australia and New Zealand (Standards 2012). Published December 2012. https://www.pharmacycouncil.org.au/ standards/standards_pharmacyprograms2014.pdf. Accessed March 10, 2020.

13. Wingfield J, Bissell P, Anderson C. The scope of pharmacy ethics-an evaluation of the international research literature, 19902002. Soc Sci Med. 2004;58(12):2383-2396.

14. Myers JR, Kiersma ME, Plake KS. Assessment of student pharmacists' ethical decision-making. Curr Pharm Teach Learn. 2017;9(6):996-1002.

15. Eckles RE, Meslin EM, Gaffney M, Helft PR. Medical ethics education: where are we? where should we be going? a review. Acad Med. 2005;80(12):1143-1152.

16. Spies AR. Plaintiff or defendant: using legal cases to teach students pharmacy law. Am J Pharm Educ. 2008;72(5):1-6.

17. Horton ER, Morin A, Pervanas HC, Mukherjee SM, Belliveau P. A novel structured format for engaging pharmacy students in bioethics discussions. Am J Pharm Educ. 2014;78(9):1-7.

18. Malcom DR. Teaching and assessing clinical ethics through group reading experience and student-led discussion. Curr Pharm Teach Learn. 2018:1-9.

19. Miller GE. The assessment of clinical skills/competence/ performance. Acad Med. 1990;65(9 Suppl):S63-67.

20. Australian Medical Council Limited. Workplace-based assessment. https://www.amc.org.au/assessment/pathways/standardpathway/workplace-based-assessment-standard-pathway/. Accessed March 10, 2020.

21. Al-Eraky M, Marei H. A fresh look at Miller's pyramid: assessment at the 'Is' and 'Do' levels. Med Educ.

2016;50(12):1253-1257.

22. Wingfield J, Wilson $\mathrm{K}$, Hall S. What the APPLET project has done to progress law and ethics teaching. Pharm J.

2005;275(7373):549-550.

23. Gallagher CT. Assessment of levels of moral reasoning in pharmacy students at different stages of the undergraduate curriculum. Int J Pharm Pract. 2011;19(5):374-380.
24. Gallagher CT. Building on bloom: a paradigm for teaching pharmacy law and ethics from the UK. Curr Pharm Teach Learn. 2011;3(1):71-76.

25. Roche C, Thoma S, Wingfield J. From workshop to e-learning: Using technology-enhanced "Intermediate concept measures" as a framework for pharmacy ethics education and assessment.

Pharmacy. 2014; 2(2):137-160.

26. Sharp E. Problem-based learning in a large pharmacy law class. Pharm Ed. 2015;15(1):105-107.

27. Chaar B, Brien J, Krass I. Professional ethics in pharmacy: the Australian experience. J Pharm Pract. 2010;13(3):195-204.

28. Queddeng K, Chaar B, Williams K. Emergency contraception in Australian community pharmacies: a simulated patient study. Contraception. 2011;83(2):176-182.

29. Semple SJ, Hotham E, Rao D, Martin K, Smith CA, Bloustein GF. Community pharmacists in Australia: barriers to information provision on complementary and alternative medicines. Pharm World Sci. 2006;28(6):366-373.

30. Chaar B. Professional ethics in pharmacy practice: developing a psychometric measure of moral reasoning. Pharm World Sci. 2009;31(4):439-449.

31. Tong A, Sainsbury P, Craig J. Consolidated criteria for reporting qualitative research (COREQ): a 32-item checklist for interviews and focus groups. Int J Qual Health Care.

2007;19(6):349-357.

32. Chaar B. Ethical dilemmas: Are you across the EHC guidelines? Aust Pharm. 2016;35(11):70.

33. Chaar B. Ethical dilemmas: Between a rock and a hard place Andrew's predicament. Aust Pharm. 2012;31(9): 746.

34. Chaar B. Ethical dilemmas: Decisions, decisions, decisions. . .ethical dilemmas in practice! Cover Story. Aust Pharm. 2006;25(6):444-449.

35. Chaar B. Ethical dilemmas: Deepening our commitment to the profession: introducing the Oath of Pharmacy. Aust Pharm.

2014;33(11):70.

36. Chaar B. Ethical dilemmas: Ethical dimensions of conducting MedsCheck. Aust Pharm. 2013;32(11):74.

37. Chaar B. Ethical dilemmas: Legal but unethical? The case of CPAP services in pharmacy. Aust Pharm. 2014;33(9):69.

38. Chaar B. Ethical dilemmas: Off-label dispensing: An ethical and legal dilemma. Aust Pharm. 2008;27(1):56-59.

39. Chaar B. Moral reasoning in healthcare professions. Phys Ther Rev. 2012;17(1):202-203.

40. Chaar B. The new Code of Ethics for pharmacists. Aust Pharm. 2012;31(2):127.

41. Richards L. Handling Qualitative Data: A Practical Guide. 3rd edition. London, UK: Sage Publications, Inc; 2005.

42. Srivastava P, Hopwood N. A practical iterative framework for qualitative data analysis. Int J Qual Methods. 2009;8(1):76-84.

43. Strauss A, Corbin J. Basics of Qualitative Research: Techniques and Procedures for Developing Grounded Theory. 4th edition.

Thousand Oaks, CA: Sage Publications, Inc; 1998.

44. The Australian Pharmacy Council. Accreditation standards for pharmacy degree (Australia/New Zealand) and intern training programs (Australia) (APC Review of the Accreditation Standards for Pharmacy Programs 2019). Published June 2019. https:// www.pharmacycouncil.org.au/standards-review/. Accessed March $10,2020$.

45. Macro CA, Lu DW, Stettner E, Sokolove PE, Ufberg JW, Noeller TP. Ethics curriculum for emergency medicine graduate medical education. J Emerg Med. 2011;40(5):550-556. 


\section{American Journal of Pharmaceutical Education 2020; 84 (3) Article 7452.}

46. DuBois J, Burkemper J. Ethics education in U.S. medical schools: a study of syllabi. Acad Med. 2002;77(5):432-437. 47. Loewy EH. Textbook of Medical Ethics. 1st edition. New York, NY: Plenum Publishing Corporation; 1989.

48. Pence GE. Classic Cases in Medical Ethics: Accounts of Cases that have Shaped Medical Ethics, with Philosophical, Legal, and Historical Backgrounds. 4th edition. New York, NY: McGraw-Hill; 2003.

49. Fleetwood J, Vaught W, Feldman D, Gracely E, Kassutto Z, Novack D. MedEthEx Online: A computer-based learning program in medical ethics and communication skills. Teach Learn Med. 2000;12(2):96-104.

50. Volandes AE. Medical ethics on film: towards a reconstruction of the teaching of healthcare professionals. J Med Ethics. 2007;33(11):678-680.

51. Pharmaceutical Society of Australia. Code of Ethics: About the Code. https://www.psa.org.au/membership/ethics/. Accessed March 10, 2020.

52. Quay S. Balancing the ethical and commercial pressures of community pharmacy. https://www.pharmaceutical-journal.com/ opinion/blogs/balancing-the-ethical-and-commercial-pressures-ofcommunity-pharmacy/20204120.blog? Accessed March 10, 2020. 53. Paola S. Big changes to pharmacist Code of Ethics. https:// ajp.com.au/news/big-changes-pharmacist-code-ethics/. Accessed March 10, 2020.

54. Brooker C. A question of ethics. https://ajp.com.au/news/aquestion-of-ethics/. Accessed March 10, 2020.

55. Hyppölä H, Kumpusalo E, Virjo I, et al. Evaluation of undergraduate medical education in Finnish community-oriented and traditional medical faculties: a 10-year follow up. Med Educ. 2000;34(12):1016-1018.

56. Watmough S, Garden A, Taylor D. Educational supervisors evaluate the preparedness of graduates from a reformed UK curriculum to work as pre-registration house officers (PRHOs): a qualitative study. Med Educ. 2006;40(10):995-1001.

57. Watmough S, O'Sullivan H, Taylor D. Graduates from a traditional medical curriculum evaluate the effectiveness of their medical curriculum through interviews. BMC Med Educ. 2009;9(64):1-7.

58. Musselman EG. Using structured debate to achieve autonomous student discussion. Hist Teach. 2004;37(3):335-349.

59. Johnston D, McInerney P, Oluwafolajimi F, et al. Experiences of medical and pharmacy students' learning in a shared environment: a qualitative study. Afr J Health Prof Educ. 2015;7(2):183-186.

60. Randolph DS. Student perceptions of the use of debate as a teaching strategy in the allied health professions. J Allied Health. 2007;36(1):e13-e29.

61. Schuwirth LWT, Van Der Vleuten CPM. The use of clinical simulations in assessment. Med Educ. 2003;37(1):65-71.

62. Bray BS, Schwartz CR, Odegard PS, Hammer DP, Seybert AL. Assessment of human patient simulation-based learning. Am J Pharm Educ. 2011;75(10):1-10.

63. Norcini J, Anderson B, Bollela V, et al. Criteria for good assessment: consensus statement and recommendations from the Ottawa 2010 conference. Med Teach. 2011;33(3):206-214.

64. Van der Vleuten CPM, Schuwirth LWT, Scheele F, Driessen EW, Hodges B. The assessment of professional competence: building blocks for theory development. Best Pract Res Clin Obstet Gynaecol. 2010;24(6):703-719.

65. Yarber L, Brownson CA, Jacob RR, et al. Evaluating a train-thetrainer approach for improving capacity for evidence-based decision making in public health. BMC Health Serv Res. 2015;15(1):547.

66. Park E, Yoon J, Choi EK, et al. A train the trainer program for healthcare professionals tasked with providing psychosocial support to breast cancer survivors. BMC Cancer. 2018;18(1):45.

67. Zhou Q, Stewart SM, Wan A, et al. Development and evaluation of a train-the-trainer workshop for Hong Kong community social service agency staff. Front Public Health. 2017;5(15):1-13.

68. Orfaly RA, Frances JC, Campbell P, Whittemore B, Joly B, Koh $\mathrm{H}$. Train-the-trainer as an educational model in public health preparedness. J Public Health Manag Pract. 2005;11(6):123-127. 69. Lane AJ, Mitchell CG. Using a train-the-trainer model to prepare educators for simulation instruction. J Contin Educ Nurs.

2013;44(7):313-317. 


\section{American Journal of Pharmaceutical Education 2020; 84 (3) Article 7452.}

Appendix 1. Topic Guide for Interview Discussions

Can you tell me a little bit about yourself and how you came to be teaching in this area of ethics?

Can you briefly describe how ethics is taught within the pharmacy program within your faculty?

What didactic content/material is provided to students during lectures? (ie, bioethics, decision-making, moral theory, religion, personal ethics)

How is the material delivered? (ie, lectures, tutorials, small group discussions)

How is the material assessed in ethics? (ie, final exam, separate assessment)

What types of resources do you use to teach ethics? (ie, specific textbooks, case-studies, own compilation)

Do you think it would be useful to have access to a specially designed reference material relating to ethics teaching that is specific for the Australian/NZ practice setting?

Do you have any other comments that you would like to add about the issues we've discussed today or ethics teaching in pharmacy in general? 